\title{
Monkeypox in Nigeria: a case report of re-emerged disease outbreak
}

\begin{abstract}
We report the case of monkey pox outbreak; a rare infectious disease that remerged and amplified the gaps in the Nigeria health system. Monkey pox, a member of the genus Orthopoxvirus and the family Poxvirida is an uncommon zoonotic disease, linked basically to the safety and unhygienic preparation of meats from animals used for 'delicacies' that are reservoir of the virus. A total of 172 suspected and 61 laboratory-confirmed cases were reported in 14 States of Nigeria. The clinical signs include enlarged lymph nodes, especially the sub-mental, submandibular, cervical, and inguinal nodes. Transmission is in two modes-animal to human and human to human. Prevention of contact with natural hosts of the virus will help to break the transmission from animal to human. Avoidance of contact with the body fluids and personal items of infected persons will prevent human-human transmission.
\end{abstract}

Volume 6 Issue 2 - 2018

\section{Okareh OT, Morakinyo OM}

Department of Environmental Health Sciences, University of Ibadan, Ibadan

Correspondence: Okareh OT, Department of Environmental Health Sciences, Faculty of Public Health, College of Medicine, University of Ibadan, Ibadan, Oyo state, Nigeria, Tel 2348062208354, Email dapsy200I@yahoo.co.uk

Received: January 27, 2018| Published: March 20, 2018

Keywords: monkeypox, orthopoxvirus, zoonotic disease, family poxvirida

\section{Introduction}

Bush meat hunting and consumption is a common practice in rural communities and urban centers because of its delicacy and for-profit purposes. ${ }^{1,2}$ It is a term for meat from wild animals that are slaughtered and prepared for personal consumption or sold traditionally in Nigeria and other parts of the world. It is a source of income for many and to a larger extent, for food. Although the name 'bushmeat' is synonymous with animals such as apes and monkeys, it also comprises rodents, reptiles, birds, elephants among others. Feeding on meat from these animals may constitute a public health risk because the hunted animals may be carriers of bacterial and viral pathogens who are causative agents of diseases of public health importance. Such diseases include Ebola, Rift Valley fever, rabies, anthrax, monkeypox etc. ${ }^{3}$ In the DRC in 1997, animals caught from the wild were tested for the monkeypox virus. Hutin et al., ${ }^{4}$ in establishing the cause of monkeypox disease, the following animals were found to have neutralizing antibodies against the monkeypox virus, suggesting a role as natural reservoirs: domestic pig (Sus scrofa), Gambian rat (Cricetomys emini), elephant shrew (Petrodromus tetradactylus), Thomas's tree/rope squirrel (Funisciurus anerythrus), Kuhl's tree squirrel (Funisciurus congicus), and sun squirrel (Heliosciurus rufobrachium). An example of the animals in the wild commonly hunted for consumption in Nigeria is the monkey, which is shown in (Figure 1) (Figure 2).

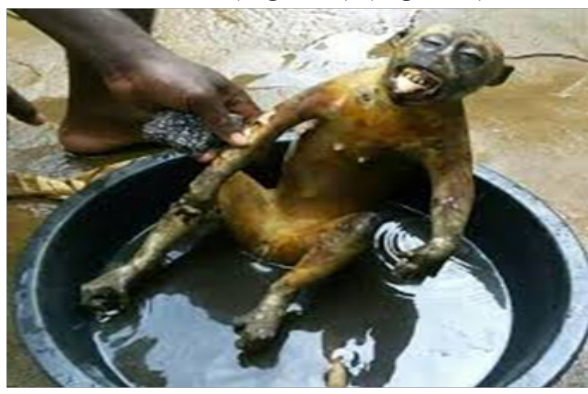

Figure I Scalded Monkey

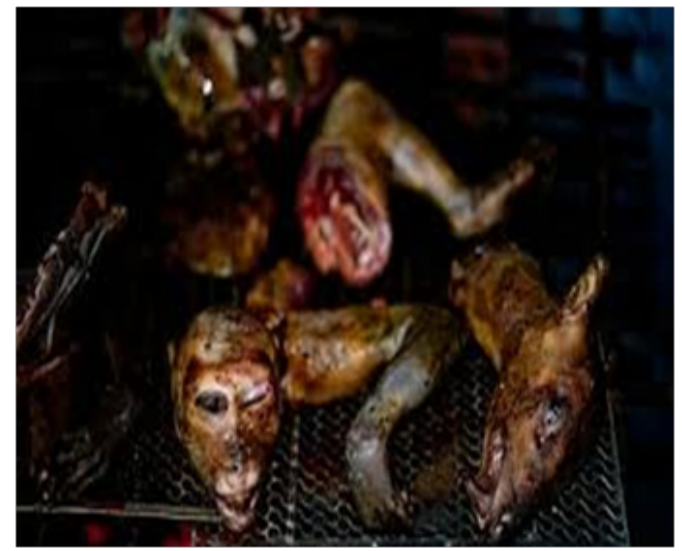

Figure 2 Cut monkey meat

\section{Case}

Monkeypox, a member of the genus Orthopoxvirus and the family Poxvirida is an uncommon zoonotic disease that is prevalent in forested areas of Central and West Africa with a fatal illness. The virus was first identified in Denmark in 1958 and has human monkeypox (formerly known as Zaire) in 1970 in the Democratic Republic of Congo. In Nigeria, the first outbreak occurred in 1971, the second outbreak in 1978 and a re-emergence on 20 September 2017 in Bayelsa State. A total of 172 suspected and 61 laboratory-confirmed cases were reported in 14 States of the Federation. ${ }^{5}$ Monkeypox can cause a syndrome clinically similar to smallpox but overall is less infectious and less deadly. The incubation period averages 12 days, ranging from 4-20 days. The most reliable clinical sign differentiating monkeypox from smallpox and chickenpox is enlarged lymph nodes, especially the sub-mental, submandibular, cervical, and inguinal nodes. ${ }^{6}$ Figure $3 \mathrm{~A}-3 \mathrm{C}$ shows patients suffering from monkeypox in Nigeria. For laboratory analysis of the monkeypox, a viral culture 
should be obtained from an oropharyngeal or nasopharyngeal swab. A skin biopsy specimen of the vesiculo pustular rash or a sample of the roof of an intact vesiculo pustule should be analyzed. Tissue for PCR of DNA sequence-specific for the monkeypox virus may be obtained. Paired sera for acute and convalescent titers may be analyzed. Serum collected more than 5 days for IgM detection or serum collected more than 8 days after rash onset for IgG detection is adjudged most efficient for the detection of the monkeypox virus infection. ${ }^{6}$
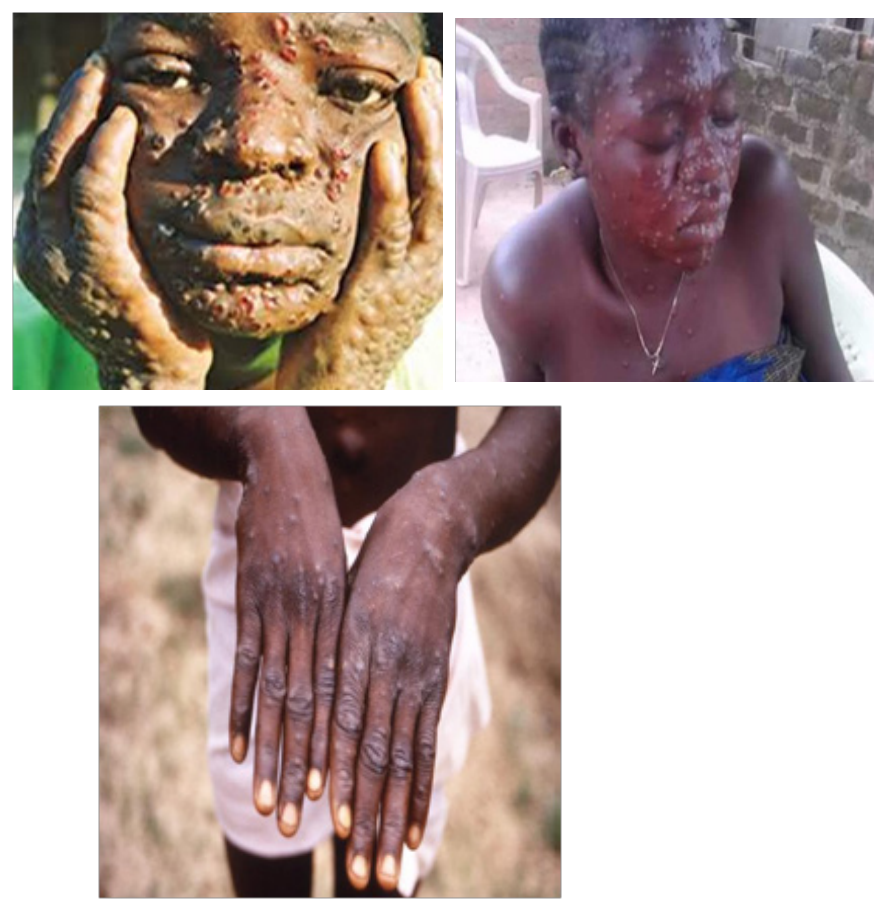

Figure 3A, B \& C Patients with monkey pox.

Transmission of monkeypox disease is in two modes-animal to human and human to human. The prevention of contact with natural hosts of the virus-monkeys, rodents, rats, squirrels and others will help to break the transmission from animal to human. The avoidance of contact with the body fluids and personal items of infected persons will help to prevent human-human transmission. Despite several awareness campaigns and health talks on the dangers associated with having contacts with body fluids and lesions of monkeys during hunting, slaughtering and bush preparation, most Nigerians said they can't stop eating the delicacy. Some excerpts of the perception of some individuals include:

"I'm still eating monkey meat. There is no risk of contracting monkeypox. I don't believe that the disease is caused by eating monkey meat."

"This is how they said Ebola is caused by bushmeat. We wash ours here and cook it very well, the government officials who are handling the campaign against the disease should not use their job to kill the business of others."

"Local hunters who supply me assorted bushmeat still brings it to my restaurant."

"Even medical doctors come to this restaurant...so why do they still come even as at Friday night, they were here and we enjoyed monkey meat together"?
Interviewees were of the general opinion that the government and all stakeholders should emphasize hygiene as a priority over blacklisting of bushmeat consumption. In Nigeria, monkeypox disease could be linked to food safety and hygiene as most people who use meat from wild animals as 'delicacies' exhibit poor knowledge of the virus, including safe and hygienic method of preparing the meat. With no available protective vaccine, no specific treatment, and no cure, there is the need to raise awareness about the risk factors of monkey pox and employ food safety education about the measures that must be taken to reduce exposure to the virus. Although smallpox vaccination may offer some protection against monkeypox, this should not be used to guard against monkeypox. Although, $\mathrm{CDC}^{8}$, recommended that anyone who has had close contact with humans or animals infected with monkeypox, or has helped to care for them, should be vaccinated against smallpox. The vaccination can be administered as late as 14 days after exposure to the virus. The $\mathrm{CDC},{ }^{8}$ also recommended that veterinarians or public health personnel conducting field investigations should be vaccinated before any exposure to monkeypox. Cats, dogs, or other mammals that have been in contact with an animal known to have monkeypox should be kept in quarantine for 30 days from the date of exposure. Pets with symptoms of monkeypox should not be taken to an animal shelter or released into the wild; instead they should be isolated from humans and other animals. Prohibition of importation, exportation, sales and distribution of pets, rodents and other mammals from geographical location known for incidences of this disease should be advocated. ${ }^{9}$

\section{Conclusion}

Monkeypox is a re-emerging disease in Nigeria with case fatalities. Since there is no specific treatment or vaccination to prevent the disease in human, there is the need for the enlightenment of the populace on the dangers associated with having close contact with wild animals as well as to disabuse their minds about their perception on the causes of monkeypox disease. It is also pertinent that the existing law on meat inspection which stipulates the mandatory inspection of animals before and after slaughtering must be enforced.

\section{Acknowledgements}

None.

\section{Conflict of interest}

The author declares no conflict of interest.

\section{References}

1. Milner-Gulland EJ, Bennett EL. The SCB 2002 Annual Meeting Wild Meat Group. Wild meat: the bigger picture. Trends in Ecology and Evolution. 2003;18(7):351-357.

2. Nasi R, Brown D, Wilkie D, et al. Conservation and use of wildlife-based resources: the bushmeat crisis. CBD Technical Series 33. Secretariat of the Convention on Biological Diversity. Montreal, Canada, and Center for International Forestry Research, Bogor, Indonesia. 2008. 50 p.

3. Klein PN. Game Meat: A Complex Food Safety and Animal Health Issue. Food safety magazine. 2005.

4. Hutin YJ, Williams RJ, Malfait $P$, et al. Outbreak of human monkeypox, Democratic Republic of Congo, 1996 to 1997. Emerg Infect Dis. 2001;7(3):434-438.

5. http://www.who.int/csr/don/21-december-2017-monkeypox-nigeria/en/ 
6. Karem KL, Reynolds M, Braden Z, et al. Characterization of acutephase humoral immunity to monkeypox: use of immunoglobulin $\mathrm{M}$ enzyme-linked immunosorbent assay for detection of monkeypox infection during the 2003 North American outbreak. Clin Diagn Lab Immunol. 2005;12(7):867-872.

7. Shedrack F, Nwakamma N. Monkey Pox: Bayelsa Protein Consumers Defy Warning, Insist Bushmeat is Safe. Metro watch. 2017.
8. https://www.cdc.gov/ncezid/dhcpp/mission_statement.html

9. Sejvar JJ, Chowdary Y, Schomogyi M, et al. Human monkeypox infection: a family cluster in the midwestern United States. J Infect Dis. 2004;190(10):1833-1840. 